\title{
(Climital Remarks
}

ON THE

\section{VALUE OF BLOOD EXAMINATION.}

Bт H. BATTY SHAW, M.D., F.R.C.P.,

ASSISTANT PHYSICIAN TO ONIVERSITY COLLEGE HOSPITAL AND TO THE HOSPITAL FOR CONSUMPTION AND DISEASES OF THE CHEST,

BROMPTON ; FELLOW OF UNIVERSITY COLLEGE, LONDON

$\triangle N D$ LECTURER IN THERAPEUTICS, UNIVERSITY

COLLEGE HOSPITAI. MEDICAL SCHOOL.

There can be little doubt that a great deal of the progress of modern medicine is based upon an appeal to methods of investigation which, in comparison .with older ones, have given to medicine a precision in diagnosis which was hitherto unknown. This tendency does not remain satisfied with past achievements, and every year the medical profession is asked to consider some.new diagnostic test, so that the older members of the profession may well suffer from a metaphorical breathlessmess in their efforts to keep pace with the newer revelations of the laboratory. The younger members of our profession are not without their disquietudes, for the same inevitable dednction is brought home forcibly to them that in order to equip themselves thoroughly for the duties before them, they must plan their careers on lines very different to those of their medical forefatheris.

In no department of clinical investigation have such strides been made as in the examination of the corpus. cular contents of the bload, and it is not out of place to consider from the point of view of the practitioner whether really, after all, the extra toil expended in such examinations is recompensed in any adequate way. Is it worth a practitioner's sacrifice of time and money, to equip himself with the instruments and facility to carry out an ordinary blood examination? Buch a question when looked at from the point of view of a busy practititioner, harassed by a thousand and one anxieties in his routine work, is a very cogent one. It may well be asked whether, after all, the number of diseases which can be positively diagnosed by an appeal to the microscopic examination of the blood is for an ordinary practitioner in this country not a very limited one. The answer is, that such cases are very limited, for amongst 1,117 medical cases, including men and women who were admitted to University College Hospital during one year, there were only 20 cases of chlorosis, secondary anaemia, leucocythaemia, lymphadenoma, pernicious anaemia, malaria, and splenic anaemia; that is, something less than 2 per cent. of the total of cases so ill as to require ward treatment could not be certainly diagnosed without the special appeal to the microscope. It is, however, obvious that this 2 per cent. does not represent all the cases in which the clinical pathologist was asked to report on the microscopic appearances of the corpuscular elements of the blood; no doubt numerous other cases of glandular enlargement; of enlargement of the spleen and liver, were examined with negative results, not to mention those cases occurring in our hospitals which are so full of enigmas as to require an appeal to special methods, if for no other purpose than one of exclusive diagnosis. There is no doubt, however, that it happens to many of us that, in the press of work, we make an appeal to the laboratory rather too often to please the minds of those fellow workers who are anxious to equip the student with that ready otock-in-trade of clinical facts which has come down to ns as a rich inheritance from the physicians of ithe past-the men who have made "clinical medicine," and especially the form of it developed by British workers, a specially unique and valuable asset. The perusal of some modern textbooks designed for use in the clinical laboratory shows only too clearly that there:is a risk, and a very great one, that our stadentsand those qualified practitioners who, with worthy self-sacrifice, return to their hospitals for courses of postgraduate work after a few years in practice, are given work to do which can have no practical value. If any one doubts this statement let him peruse the chapters on chemical pathology of many quite recent guides to work in the clinical laboratory; let him peruse the stont volumes which concern themselves, with the opedial examination of the blood, not of dieeases wuch as heve been enumerated above, but in numerous infections. To sift any real value from those husks of chemical and haematological exercises may well defy us and bring into undeserved disrepute methods of investigation which when properly directed are absolutely invaluable. No practitioner will ever complain of microscopic examina tion which will make diagnosis certain, and though unfortunately he may not receive much assistance in a positive sense in the direction of treatment, even when a case of leucocythaemia or pernicious anaemia has been diagnosed by these methods, he will at least be prevented from carrying out treatment based on a wrong conception of the malady as derived from ordinary clinical methods. It has been my experience to know of a case of unsuspected per. nicious anacmia to be operated upon because of persistent vomiting and some abdominal pain which appeared to develop after a "run over" wagon accident twelve month previously, and of splenectomy being performed for the removal of an pnlarged organ from a leucocythaemic patient who had had malaria'some years previously.

A timely blood examination would have in both cases discovered important facts, and shown them to be cases of grave blood disease. It is a regrettable fact that both cases died not many hours after the operation. Still another case of an elderly subject was admitted for enlargement of glands of the neck suspected to be tubereulous or lymphadenomatous; a precautionary suggestion on the part of the surgeon that the blood should be examined saved a difficulty, for the case. was readily established to be one of leucocythaemia, and death occurred quite unexpectedly within a few days of admission. Similar cases could be readily cited to show that it is absolutely necessary in certain cases of doubt that an appeal should be made to the microscope.

The value of positive findings can in no way be belittled by the frequent occurrence of negative ones; the latter will be small in proportion as the practitioner is well trained clinically, and is able to suspect just those cases which do not accurately correspond. with examples of disease in which no gross corpuscular alteration of the blood is a feature.

One is well aware that such remarks as the above have no special value for those who have access to our hospitals and laboratories; to them, reference to the numerous contradictions met with in blood examinations would be more palatable; to the general practitioner, however, far removed from centres of research, there is the certainty that the simple assurance of the value of the blood examination with reference to corpuscular content will come with a large degree of welcome. To quote a few examples of the way in which one blood disease alone can assume clinical similitudes, I can call to mind cases of leucocythaemia which were, prior to blood examination, considered to be " septicaemia," "scurvy," "gangrenous stomatitis,". "diphtheria," "lymphadenoma," "tuberculosis of the lungs,". " appendicitis," "malaria," and "tuberculous peritonitis." To the general practitioner hesitating about the valne of blood examination, such an array of wrong diagnoses will remove any vestiges of doubt, especially as they were met with in the very short experience of one who has, however, the advantage of an appeal to a clinical laboratory.

There remains another field of observation on the corpuscular contents of the blood, to which hopeful attention has been turned by many observers, and by none mare intently than the surgeons. ' It has long been recognized that suppuration is closely associated with an increase in the leucocy.tic content of the blood, and an effort has been :made to make use of this reaction as a means of diagnosing the existence of foci of suppraration which lraverfailed to be detected by the simple methods of clinical investigation. Thus efforts have been made by this means to detect the presence of intracramial suppuration in association with otitis media, to determine the existence of empyemata, of suppurative osteitis farremoved from any ordinary clinical detection, and above all to discover suppuration and gangrene, in appendicitis, a dis ease of which, even at the present day, it may well be said that special considenation is needed for ceach individual case; unfortunately even then there may ibe'want of unanimity between the surgeon and physician, or, in the caise of a general praotitioner, between his surgical and medical instinots. Probably, however, there will be little diffenence of opinion on one point at least, and that

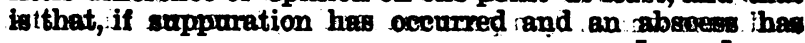


formed, the sooner evacuation can be secured the safer for the patient. It is a very unfortunate thing that observations on leucocytosis occurring in appendicular suppuration should not have yielded clear evidence on this point; suppuration may have occurred, and yet not have provoked leucocytosis; leucocytosis may have developed even to the extent of an increase of the total leucocytes to three times their number, and yet suppuration may be absent as a feature of the lesion affecting the appendix.

Opinions further differ very much upon the question of degree of leucocytosis, some observers hesitating to diagnose a suppurative process until the leucocytosis is very extreme. It is therefore not to be wondered at that there is much hesitation in attaching any value to this form of investigation as a means of deciding the advisability or not of immediate operation. Quite apart from this objection, there is another very practical one-namely, that it is not always possible to delay till even such a simple matter as a leucocyte count can be carried out; to the inexpert it is tedious, and to obtain the help of others may mean considerable trouble and delay-both drawbacks, the removal of which, however, if necessary for the welfare of the patient, should be possible, though the difficulty in the case of our hospitals of enthusing a housephysician or house-surgeon to carry out a blood examination at late hours of the night, which is a common time for the arrival of such cases in the casualty room, is a real one.

That we should not abandon blood examination in suspected suppuration is shown by a contribution in the Annals of Surgery for this year. Dr. C. L. Gibson does not lay such stress upon mere high grades of leucocptosis as being diagnostic of suppuration. Hyper-leucocytosis includes any increase over 10,000 , but, as he points out, some other change than mere leucocytosis is necessar before it can be confidently stated that suppuration has occurred. Leucocytosis with a moderate increase of polymorphonuclear cells may mean merely a localized infection and limited absorption, whereas even moderate leuco. cytosis and a notable polymorphonuclear increase means one of two important conditions-(a) a severe lesion, or (b) a diminished resistance to absorption.

Dr. Gibson considers that inflammatory reactions which are well resisted produce such corpuscular alteration of the blood that the polymorphonuclear cells are increased approximately one degree (taking their normal percentage to be 75 of the total leucocytes of the blood) for every increase of 1,000 leucocytes above 10,000. In acute surgical cases in which-for example,"say, in appendicitissuppuration or gangrene has taken place, the increase of the polymorphonuclear cells is greater per 1,000 of the total leucocytic count than when resistance is well maintained. When such statements are made, the old question at once recurs as to whether the condition of suppuration and gangrene can exist in the absence of this interesting and peculiar increase in the relative proportion of the polymorphonuclear cells. Dr. Gibson's answer is that negative findings-that is, no relative increase of the polymorphonuclear cells or actual decrease of the proportion of those cells-show with but rare exceptions absence of severity. To the practitioner such information will come with welcome, for he probably has no more anxious experience than the management of cases of appendicitis; he can at present formulate no rule which will guide him to a timely operation. Again and again the ordinary signs of severeintoxication will be absent, and yet, unfortu. nately too often too late, the appendix is found to be gangrenous; or he may seek in vain for the signs of an abscess by ordinary means, and yet under the same sad circumstances as in gangrenous appendicitis the true state of affairs is found too late.

It is no part of my purpose to give a critical review of the progress or the reverse of blood examination. It is, on the other hand, a worthy object to attempt to bring forward a few features of this interesting study which, by reason of their foundation in careful scientific inquiry, may be confidently tried by the practitioners, who, groping hitherto in the dark by the help of older methods and older teaching, may find helpful assistance by the newer methods.

Probably all observers have been disappointed with many of the vaunted methods of cure of the comparatively trivial and yet ill-understood condition-chlorosisa disease which, by a pure convention, is restricted to the female sex, though there is little doubt that a parallel! condition occurs in boys.

Our failure to properly understand, I will not say the. cause, for that is still wrapped in obscurity, but the reactions of the body in response to the cause or causes of this disorder is very largely, if not entirely, due to ar slavish satisfaction and contentment with the readings of the haemoglobinometer. To this day the hackneyed theory of a poverty of the iron content of the red cells is repeated as an explanation of the anaemia, dropsy, and other well-known features of the disease. Because the haemoglobinometer gives readings far below the normal, and as a rule, though not invariably, shows a proportionately greater reduction than that of the red cells of the blood, we have been satisfied to give our patients "more iron during one week than the whole body contains under ordinary circumstances," and to hope for cure. It is common knowledge that cases of chlorosis will improve and recover without the use of iron in any form, and even if iron appears in some cases to effect a cure, the ordinary clinical examination of the blood, which has given us in the past a diagnostic indication and, on erroneous grounds, a pathological explanation of chlorosis, has been shown to be fallacious.

It is with the hope of dispelling this error that attention is called to an investigation which in importance ranks with the first observations that have been made on the changes of the blood in disease. I refer to the work by Dr. Haldane and Dr. J. Lorrain Smith, who have so clearly shown by their introduction of an original method of investigating the haemoglobin content of the blood and by the application of this method in the investigations of disease, that some statements which have come to be accepted as veritable corner stones of the fabric of haematology have been shown to be quite erroneous.

It is simple enough now to see why such grave errors should have been made in the past, because the teaching of Cohnheim has been accepted without question that plethors, by which is meant an increase of the volume of the blood circulating in the vessels of the body, is an impossibility. As Dr. Lorrain Smith says, this is the truth in health but in disease it is not so. It seems almost certain that here again medicine, as in other instances, has suffered by a too slavish subscription to the view that what is experimentally true for a healthy animar is true also in disease. No doubt in healthy animals the introduction into the circulation of an isotonic fluid produces no permanent increase in the total blood volume, for the kidneys, intestines, skin, and lungs soon effect an elimination from the circulation of the extra fluid, which, escaping from the blood vessels and filling the lymphatics, finds normal processes at work by which such. fluid escapes by the ordinary channels.

The two workers above mentioned bave tanght us, several years ago now, how necessary it is for us to shake ourselves loose from the older conceptions, and that it must be realized that in pathology physiology has really gone astray, and in various forms of anaemia the normal blood content of the circulation is increased ; ' in fact, the old-time use of the term "plethora " may be reintroduced, at any rate in one of its senses-namely, that in which it is meant that the fluid part of the blood, the plasma, is incressed in amount. A sort of plasmic plethora has developed, for it is known, for example, that the specific gravity of the blood in chlorosis is unaltered, although the total volume of blood has increased. Dr. Lorrain Smith has shown that in chlorosis the total amount of the haemoglobin is normal in amount, even though the readings by the haemoglobinometer give a figure much below the normal. A given unit of blood removed from $a$ patient suffering from chlorosis contains less haemoglobin than the same volume of blood removed from a healthy patient, but this is due to the fact that in this disease, for some unknown reason, the plasma is increased in quantity and there is less room in the particular volume of chlorotic blood for the number of corpuscles usually contained therein. The question at once occurs whether the unequal reduction of red corpuscles and of the haemoglobin, as estimated by various methods, does not show that $\mathrm{Dr}$. Lorrain Smith's contention is wrong-for example, the average percentage of the haemoglobin in 21 cases of chlorosis examined by Dr. Lorrain Smith and showing less than 50 per cent. of haemoglobin was 39.9 per cent, a much greater reduction than that of the red corpuscles per cubic. 
millimetre, the average of the same cases being $3,222,000$. The answer, however, to this apparent anomaly is found in a further observation by Dr. Lorrain Smith-namely, that though in such cases the number of red corpuscles per cubic millimetre may be found to be as low as $3,222,000$, the absolute number of red corpuscles is really much greater even by as much as three times or more; obviously, as the total amount of haemoglobin is normal in chlorosis each red corpuscle will contain less haemoglobin than normally is the case.

Such important work as that I have just alluded to has not received the recognition it deserves, and though it does not show us the ultimate cure of chlorosis, it does at least show that if the use of iron preparations in chlorosis does effect a cure there is no evidence that salts of iron aid in such cases "by the direct upbuilding of haemoglobin," and incidentally it offers no valid objection to the observation that chlorosis does not always respond to the use of iron or of arsenic, and will frequently yield to methods of a less pharmaceutical character.

Another investigation which in part concerns the blood, and which has been stadied very widely abroad and to a much less extent in this country, is known as "cryoscopy." As is well known, this method consists of an application of the principles of the new physico-chemistry to the estimation of the freezing point not only of the blood but of the body fluids, and thereby to ascertain-as, for example, in suspected kidney disease-whether the organ is properly performing its duty of excretion of the various soluble contents of the urine, a comparison being made in bilateral renal disease of the blood and urine with that of the normal individual, or; in the case of unilateral disease, by a comparison of the freezing point of the patient's blood with the normal and of the segregated urines from each kidney with one another and with the normal urine. The Beckmann form of cryoscope is well known in the physical laboratory, and with practice can be used with accuracy. The one general objection to its clinical use is that a considerable amount of blood needs to be drawn from the patient investigated; moreover, the preparation of the freezing mixture is often a somewhat inconvenient drawback. This difficulty as well as others is greatly resolved by the method of cryoscopy introduced by Sir Almroth Wright, ${ }^{1}$ in which the salt content of a fluid, for example, urine, is determined by a comparison of the haemolyzing power of such urine with the haemolyzing power of varying strengths of decinormal salt solution. So much is gained by the simplicity of this method over the older cryoscopic ones, that the drawback that the findings are all expressed in terms of sodium chloride is fally outweighed. Dr. O. C. Gruner has contributed a valuable paper on the applicability of both cryoscopy and observation of electro-conductivity of the various body fluids in disease, and though he adopts a most cautious attitude as to the value of these special investigations, more especially in diagnosis, he yet thinks that from the point of view of prognosis and treatment there is room for hope. From the diagnostic point of view he thinks that cryoscopy will prove of service in determining the existence of renal disease as opposed to bladder disease, or the existence of renal disease in a case of heart disease. Contrary to the earlier teaching of Kümmel and Rumpel, he does not think that cryoscopy any more than any other means of diagnosis enables one to say a kidney must or must not be removed.

There remains one last subject to which reference must be made in any contribution dealing with the investigations which have been made on the blood, the more particularly as these investigations, though based upon the reaction of the body to all sources of infection in which the causative organism has been determined, are carried out by means on the one hand of the polymorphonuclear cells of the blood, and on the other by means of the serum of the blood. So important are these investigations, not only from the diagnostic point of view, but also from the therapeutic one, that it has already been surmised that the.whole subject of medicine from the point of view of the study of infections, is experiencing a great impetus Pathogenic bacteria have now for years been studied elosely in their morphological, cultural, and pathogenic aspects; the hopeful expectations of sero-therapy have, except in two or three directions, notably in that of the diphtheria antitoxic serum, proved so disappointing that interest in bacteriological problems was beginning to give place to an interest in chemical pathology. Sir Almroth Wright, by his initiative action in the study of the opsonic content of the blood in various infectious diseases, has brought before the profession at large matters which claim the closest attention. It is not my purpose to attempt any appreciation and criticism of these newer methods, for weighted as I am with a recently acquired debt of gratitude to Sir Almroth Wright and his associates for their unfailing courtesy and patience in expounding the principles upon which these methods are based, I have but a few isolated personal experiences to draw upon; but there remains an important duty, namely, to point out what is not grasped by all who hear or read of the investigation mentioned namely, that Sir Almroth Wright's efforts have succeeded in detecting the specific action of organisms upon the body when once they have secured a footing, and in certain cases of doing so when ordinary clinical evidence of infection is indefinite, when cultural examinations of the blood are negative or when it is impossible to trace the organisms at work by the examination of pathological discharges owing to their absence. By such means it is possible to detect in certain cases a transitory infection without at any time the immediate cause of the infection being brought to view, and even by organisms which are generally believed "to come to stay." Such a possibility may well revolutionize the whole of medicine, at any rate that part of it which till recently has had to satisfy itself with the mere anatcmical localization of the seat of this or that infection. The numerous papers pub. lished in this and other countries are enough in them selves to show how deeply this new aspect of applied bacteriology is interesting the profession. Mere diagnosis, however, is but part of the modern battle with infection, there remains the therapeutic side; the same observation in the opsonic content of the blood as used in diagnosis is also indispensable in following the therapeutic effects of inoculation with the dead causative organisms-vaccination, in other words, in accordance with the nomenclature adopted by Sir Almroth Wright.

One word remains to be said of another aspect of this study. As an onlooker one is obliged to confess that, far reaching as are sure to be the results which Sir Almroth Wright and his colleagues are bringing before our notice, it is incumbent upon the medical profession, and that part of it which is especially responsible for the education of the medical student and for the further education of the qualified practitioner willing to modernize his knowledge, to see to it that our pathological laboratories are made into living institutions, not merely for the instruction in the naked-eye and microscopic appearances of the derelict organs of the body and of the organisms eausing such change, but that the bacteriological departments should be furnished and endowed with an eye to the possibilities of their conversion to therapeutic purposes. No doubt much more remains to be done to complete the details of our knowledge of the opsonic reaction, and particularly of that embodying the beneficent effects of vaccination. This, however, is impossible unless our hospital managers, following the example already set in two at least of our great hospitals, will prepare themselves for the endowment, in the first place, of expert bacteriologists for our hospitals, and, in the second, of contingents of assistants prepared to carry out the exacting details of a method of investigation which will suffer if not left in the hands of those thoroughly versed in the important principles underlying them. It is needless to say that the bacteriological laboratory under the new circumstances assumes an economic importance for our hospitals which threatens to cast into the shade the old-world pretensions of their dispensaries and the empiric value of their hydropathic and electro-theraceutic departments.

1 Lancet, October 21st, 1905. 2 Medical Chronicle, September, 1906, p. 353 .

THE award list of the International Jury at the Milan Fxhibition. which has now been issued, contains the names of Mr. Walter Dowson, M.A., M.B.Camb., and of his colleague, Dr. Barger. They seem to have been very successful, obtaining gold medals themselves and winning the Grand Prix with their exhibits illustrative of the work performed hy them in the conduct of the BurroughsWellcome Physiclogical Research Laboratory. 